\title{
Effect of Parapet Lattice on Alteration of Airflow for Convective Cooling of the Roof Surface
}

\author{
Kapil Arora, Mahua Mukherjee
}

\begin{abstract}
For reducing the thermal stress in the environment, studies are being conducted to articulate the building elements for increasing their efficacy. These elements, which are like shading devices, balcony, veranda, walls, windows, etc. are associated with superstructure but are positioned below the roof level[1][2][3]. Here, parapet, which is primarily designed for safety and aesthetics, has been explored for its ability to reduce roof surface temperature. Any modification in the design of a parapet directly influences the amount of solar gain or the pattern of airflow on the roof surface. Though the limited height of a parapet does not have much influence on the amount of solar gain or shade, it can alter the incoming airflow. Traditionally voids have been provided in parapet to facilitate passing air to get in touch with roof surface for convective cooling. So, the paper focus on designing and evaluating an array of generic voids with opening ranging from 0 to 80 per cent for the active cooling of the adjoining roof surface. For the broader benefit of the study, elements like dwelling unit size, climatic conditions, choice of building material, contemporary designs of parapet etc. have been taken consideration. Sixteen generic modules were formed, which were examined in two phases; these include CFD simulation and three-dimensional physical model study. The results established a notable difference in the rate of heat loss among themselves with respect to the timeline. On this basis, the sixteen scenarios were rearranged and grouped following the descending order of the heat loss. The application of this outcome will not only enhance the rooftop living environment but will also facilitate enhanced thermal comfort, especially to those who have either no access or have limited economic resources to manage mechanical appliances.
\end{abstract}

Keywords: Parapet, Lattice, Passive Convective Cooling, CFD, Thermal Imaging, Affordability

\section{INTRODUCTION}

Convective cooling, which is one of a well-recognized passive design strategy, has been in practice either individually or in combination with other passive techniques like evaporative cooling. This combination accelerates the cooling process, especially during clear night sky after a hot summer day. The strategy is prevalent among the residents who use their roof for post evening activities like sleeping, sitting, playing, eating etc. Sleeping on a roof is helpful for people who belong to economically weaker section (EWS) and lower-income group (LIG) as it saves their spending on electricity for achieving thermal comfort.

Revised Manuscript Received on February 05, 2020.

* Correspondence Author

Kapil Arora*, Department of Architecture \& Planning, Indian Institute of Technology Roorkee, Roorkee, India. Email: arkapilarora@gmail.com

Dr Mahua Mukherjee, Department of Architecture \& Planning, Indian Institute of Technology Roorkee, Roorkee, India. Email: mahuafap@iitr.ac.in

(c) The Authors. Published by Blue Eyes Intelligence Engineering and Sciences Publication (BEIESP). This is an open access article under the CC BY-NC-ND license (http://creativecommons.org/licenses/by-nc-nd/4.0/)
In addition to this, the exposed roof facilitates rapid cooling of surroundings in comparison to indoors, which requires time to flush out the heat gained during the day. The concept of channelling air through voids for achieving better convective cooling has been in practice for

a long time through different modes. Mashrabiya[4], which used to be a part of traditional windows in many tropical countries of Middle East Asia and was made of round wooden beads, allow diffused sunlight and air. The dry air which enters from the adjacent street was humidified after it gets brushed to an earthen pot containing water and placed next to a window. Primary it was the size, shape and design of the wooden beads which defines the pattern of airflow and diffused sunlight.

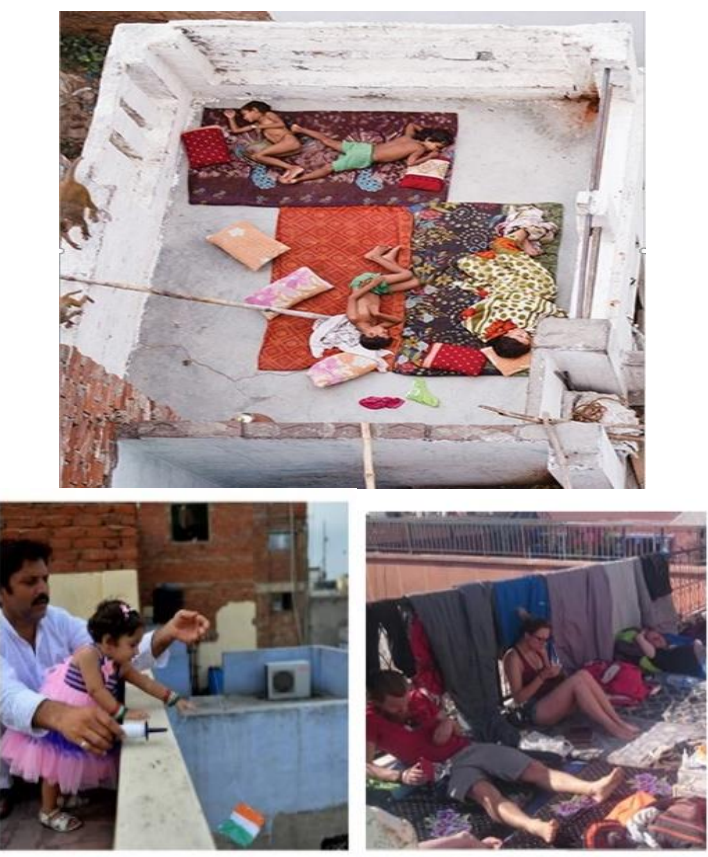

Fig. 1: Use of Roof for playing, sitting, discussion, sleeping, etc. Source:[6][7][8]

Similarly, the design of stone lattice, popularly known as stone jali, has been a part of passive design for ventilation of forts, palaces, and traditional houses in the Indian subcontinent. The design of jali was customized as per the location of its application. For increasing the rate of flow of incoming air, the jali used to be bevelled, which accommodates a sharp edge in the centre, resulting in increased air velocity due to the Venturi effect[5]. For spaces that were either below the ground level or did not have direct access to the adjoining street, courtyard, etc. they were facilitated with long and narrow air channels. 


\section{Effect of Parapet Lattice on Alteration of Airflow for Convective Cooling of the Roof Surface}

Similarly, to reduce the climatic stress caused during hot and dry seasons, the outlet of air channels was provided just above the water. When the air gets in touch with running water, it gets humidified, and the surroundings were facilitated with a calm and humid environment. Such zones

planned as a Summer Palace and were generally positioned along the northern side for least solar gain[5].

Based on the learnings and inspirations from traditional cases of convective cooling, the study intends to evaluate the behaviour of a parapet with a varied set of voids for their ability to cool down the roof surface. The intent is to provide an order of generic designs of voids for parapet which may be opted directly or with minor modifications in the upcoming or renovating projects, where substantial roof activities are expected to take place. Projects falling under hot \& dry climate or composite climate (during summers) can benefit the most because of the high diurnal temperature variation between hot days and cold nights.

\section{LITERATURE REVIEW}

A part of the study done by Mohsen discusses the process of thermal exchange between a roof and its surroundings along with the microclimatic impact of parapet walls[9]. It stated that in the process of radiation gain, the inner edges along the parapet wall receives less radiation and majorly depends on the angle of solar rays. Further, it explains the process of heat exchange by roof surface through conduction and convection, once the surface temperature reaches beyond the ambient air temperature. Mili Majumdar, the author of Energy-efficient Buildings in India, discusses a traditional way of convective cooling, which has been in practice for many years[10]. This technique of providing voids near the surface and inverted earthen pots within a roof facilitates convective cooling and insulation, respectively. Charles Correa, a famous Indian Architect, discusses the role of traditional and contemporary Indian architectural elements like chattris (umbrellas), pergola roof etc. his article 'The Blessings of the Sky'[11]. He stated that these elements translate roof to an additional room. This semi-open room has been accommodating different daily activities like cooking, group discussion, sleeping, playing etc.
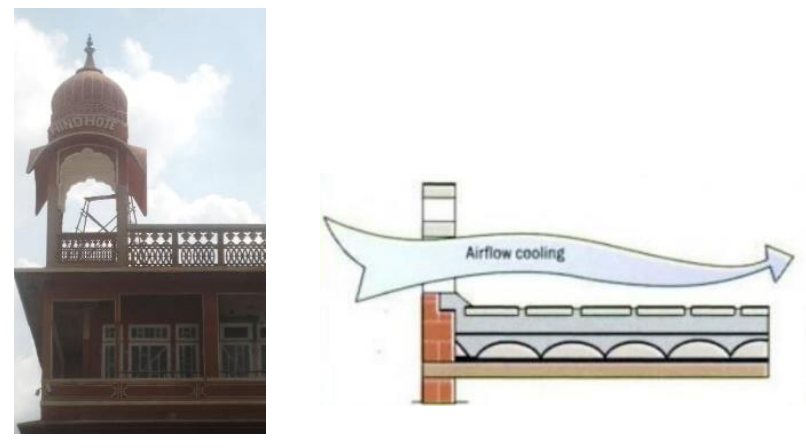

Fig. 2: Traditional elements for controlling roof temperature through solar shading and convective cooling. Source: author,[10]

\section{RESEARCH METHODOLOGY}

The evaluation of parapet modules was done in two phases. During the first phase, a total of sixteen parapet modules were evaluated using computational fluid dynamics software: ANSYS Fluent[12], which has been widely accepted by academicians, researches, industry, etc. In the second phase, two modules were picked from the original set of sixteen modules which were picked from the top and bottom of the performing order, based on phase I results. For these two modules, reduced-scale physical models were constructed and were analysed in an outdoor environment using environmental instruments like an anemometer, thermal imaging camera, digital thermometer. Later the pattern of heat loss was compared between the results generated from digital and physical models. After the comparative analysis and validation of the process of heat loss, the sixteen modules were arranged in descending order based on relative heat loss.

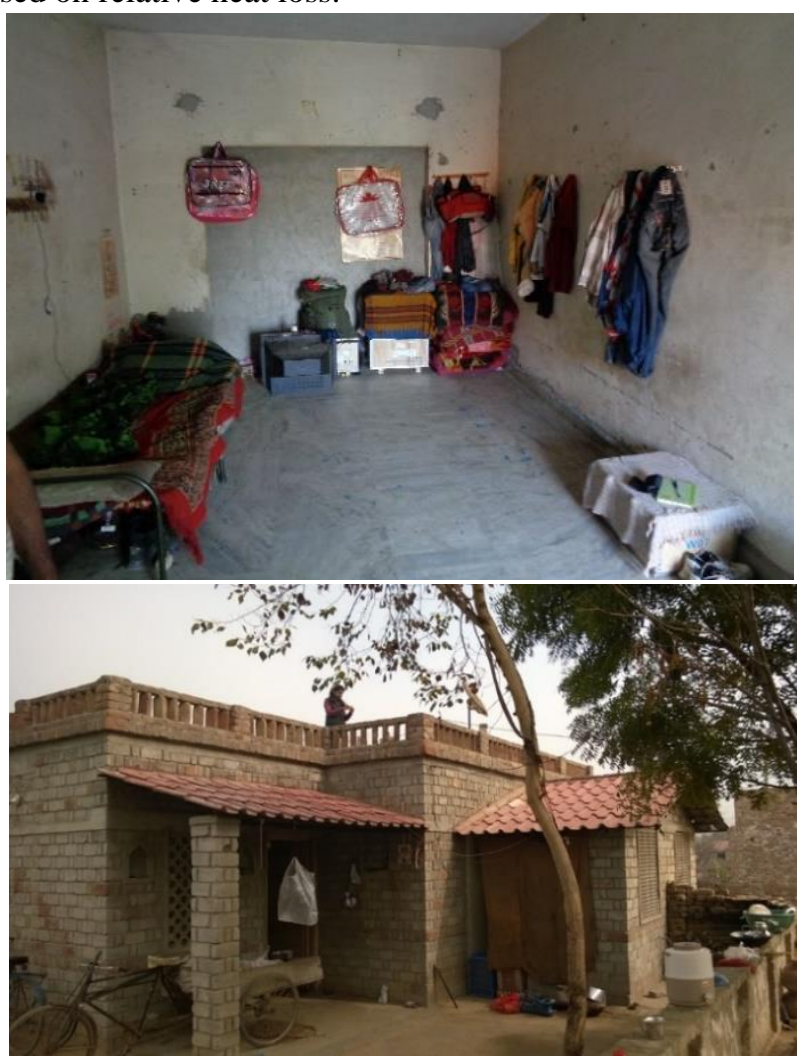

Fig. 3: EWS rented dwelling unit with on electric appliances for thermal comfort (left) and a recently constructed EWS house with perforated parapet wall. Source: author

\section{A. Phase I- CFD Simulation Study}

Generic patterns of voids were designed, which were based on a visual survey and secondary data covering contemporary and traditional parapet designs. It was observed that the percentage of opening within parapets walls primarily ranged between 0 to 80 per cent. Sixteen generic grid patterns were designed to accommodate voids with an opening percentage of $0,20,40,60$ and 80 respectively.

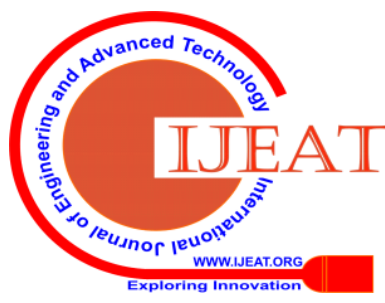



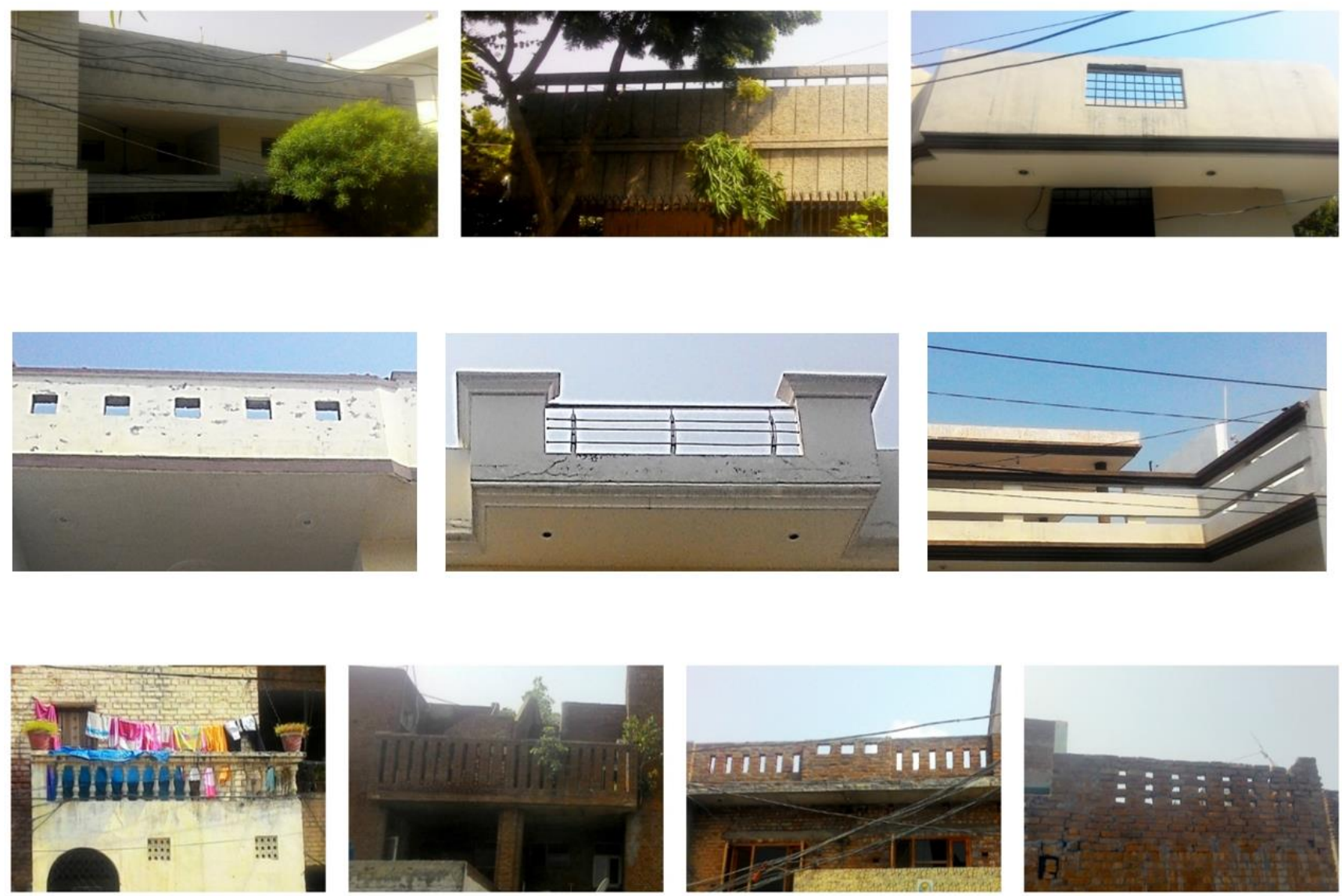

Fig. 4: Images of parapet walls with a range of solid to void ratio along with their design patterns recorded during the visual survey. Source: author

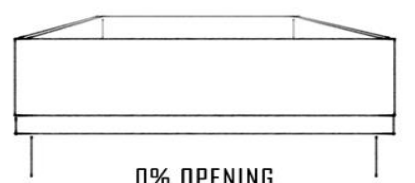

T\% OPENING

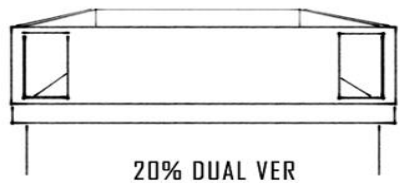

20\% DUAL VER
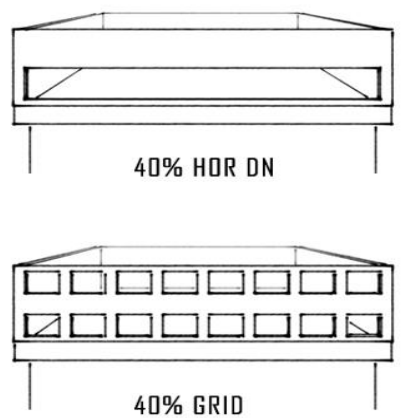
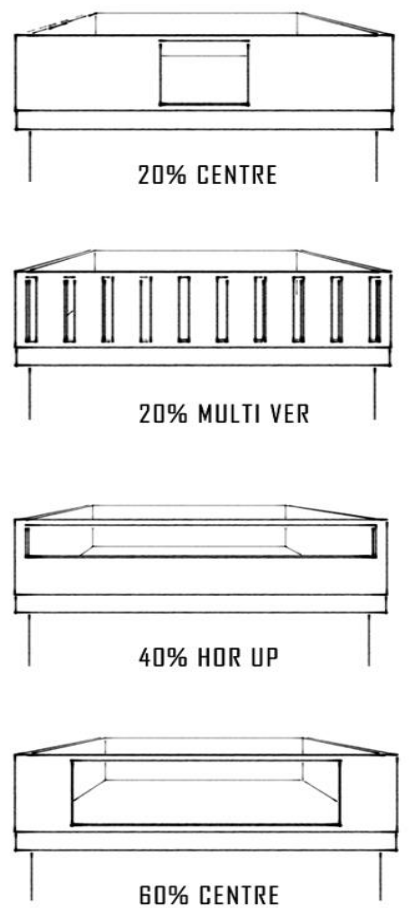

6Q\% CENTRE
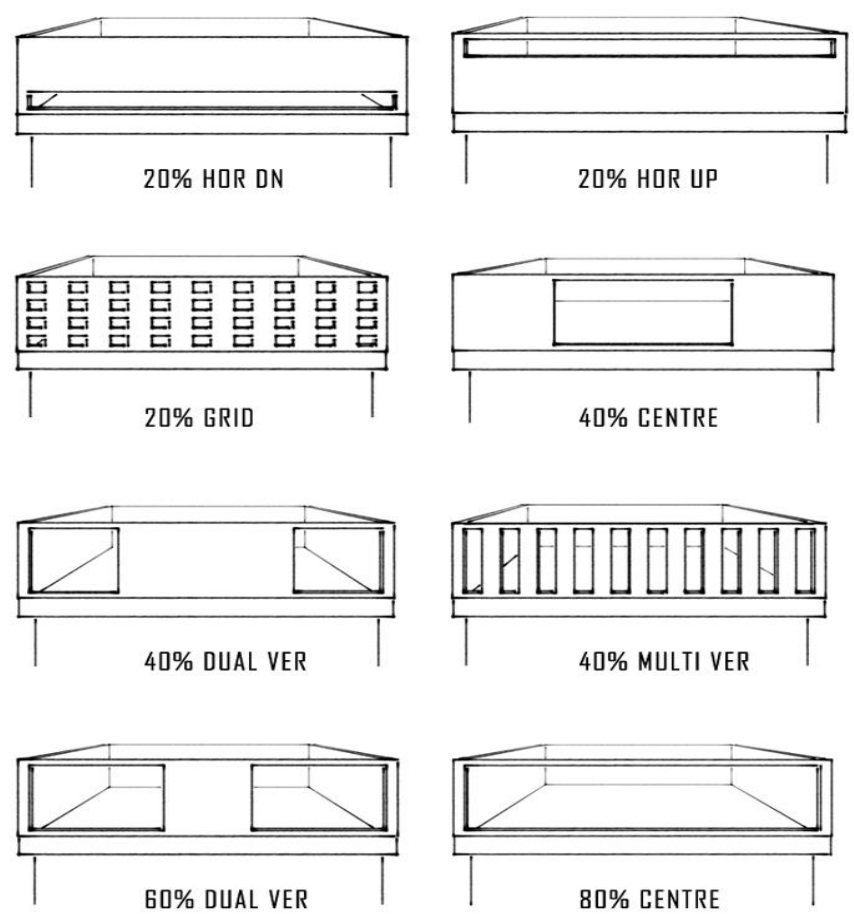

Fig. 5: Sixteen generic lattice designs for the parapet wall with void per cent ranges from 0 to 80

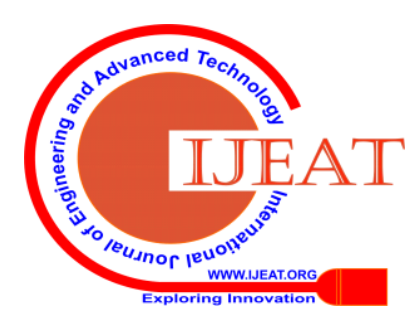


All the profiles were either square or rectangular. The order of positioning of voids broadly includes a) centrally positioned single void b) twin split voids along the vertical edges c) single void along the horizontal edges d) multiple vertical split voids along the face e) multiple check voids along the face and f) no void.

Table- I: Generic names based on the percentage of opening and their respective scenarios

\begin{tabular}{|c|l|c|}
\hline Sr. No. & Generic Name & Scenario \\
\hline 1 & $0 \%$ Opening & S1 \\
\hline 2 & $20 \%$ Centre & S2 \\
\hline 3 & $20 \%$ Horizontal Down & S3 \\
\hline 4 & $20 \%$ Horizontal Up & S4 \\
\hline 5 & $20 \%$ Dual Vertical & S5 \\
\hline 6 & $20 \%$ Multiple Vertical & S6 \\
\hline 7 & $20 \%$ Grid & S8 \\
\hline 8 & $40 \%$ Centre & S9 \\
\hline 9 & $40 \%$ Horizontal Down & S10 \\
\hline 10 & $40 \%$ Horizontal Up & S11 \\
\hline 11 & $40 \%$ Dual Vertical & S13 \\
\hline 12 & $40 \%$ Multiple Vertical & S14 \\
\hline 13 & $40 \%$ Grid & S15 \\
\hline 14 & $60 \%$ Centre & S16 \\
\hline 15 & $60 \%$ Dual Vertical & \\
\hline 16 & $80 \%$ Centre & \\
\hline
\end{tabular}

For the analysis, a digital model of a single habitable unit with a size of $4 \mathrm{~m} \times 7 \mathrm{~m} \times 3 \mathrm{~m}$ was modelled in SpaceClaim software, which was later imported in ANSYS fluent. The area of the habitable unit was like a single dwelling unit (DU) meant for an EWS family, as per the latest affordable urban housing policy framed by the Government of India. So later, the outcome can be adopted for an individual unit or multiple units planned in a row, courtyard, etc. in case the parapet wall is provided along the common wall of dwelling units. Though the proportion of DU may vary from the given profile, nonetheless the shorter face of the DU designed for EWS or LIG will certainly align along the road while
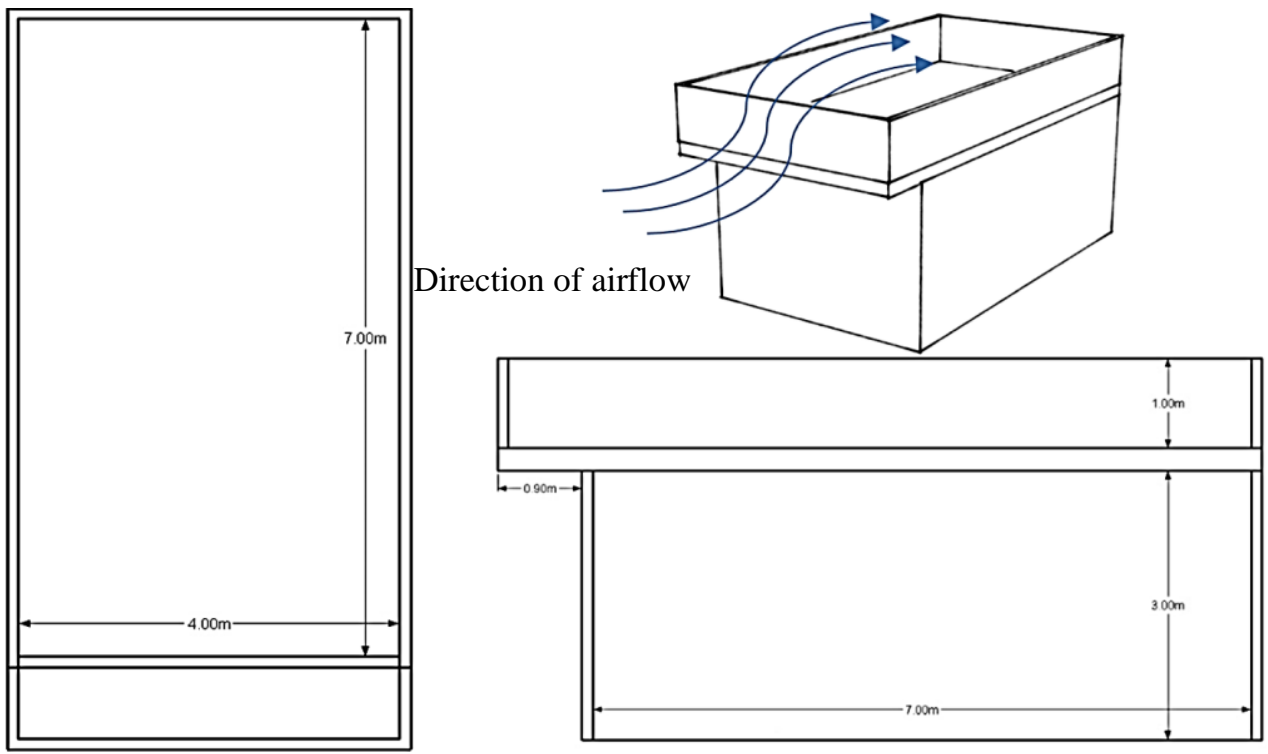

Fig. 6: Plan, section, and three-dimensional view of the unit designed for the simulation study

considering building economics. As per Indian National Code[13], a 1m high parapet wall was provided with a roof projection of $0.9 \mathrm{~m}$ on the front side. The sixteen modules of parapet were positioned turn by turn as the front parapet which were based on available or collected data from the ities falling under the composite climate of India.

i. The ambient air temperature was kept constant at 297.85 K throughout the simulation. This value was based on the average value of late evening outdoor ambient air temperature.

ii. The surface temperature of the roof was initially patched at $318.15 \mathrm{~K}$ under the average temperature of the roof surface in the afternoon during summers.

iii. The air velocity was kept constant at a rate of 3 $\mathrm{m} / \mathrm{s}$. The value was a bit higher than the average value so to maintain constant airflow. Further $3 \mathrm{~m} / \mathrm{s}$ maps with a light breeze under the Beaufort scale for wind speed[14].

iv. The direction of airflow was kept perpendicular to the facade of the parapet to limit the number of cases for simulation.

v. To analyse the impact of convective cooling by the directional airflow, all other environmental factors ke solar radiation, humidity etc. were not part of the simulation.

vi. The choice of building material was made based on contemporary building materials, which are being used widely used in the construction of EWS and LIG housing.

vii. No opening was provided in the room, so to abstain heat loss from the lower part of the roof. 
Table- II: Input and Output conditions for ANSYS Fluent Model

\begin{tabular}{|c|c|c|c|}
\hline \multicolumn{2}{|l|}{ Domain Setup } & \multirow{2}{*}{$\begin{array}{l}\text { Units } \\
\text { Density }\left(\mathrm{kg} / \mathrm{m}^{3}\right)\end{array}$} & \multirow{2}{*}{$\begin{array}{l}\text { Input Value } \\
1.177\end{array}$} \\
\hline Materials & Air & & \\
\hline & & Cp (Specific Heat) (j/kg-k) & 1004.90 \\
\hline & & Thermal Conductivity (w/m-k) & 0.02624 \\
\hline & & Viscosity (kg/m-s) & $1.846 \mathrm{e}-05$ \\
\hline & Kiln baked brick & Density $\left(\mathrm{kg} / \mathrm{m}^{3}\right)$ & 1890 \\
\hline & & Cp (Specfic Heat) (j/kg-k) & 900 \\
\hline & & Thermal Conductivity (w/m-k) & 1 \\
\hline & & Initial temperature $(\mathrm{k})$ & 318.15 \\
\hline & Concrete & Density $\left(\mathrm{kg} / \mathrm{m}^{3}\right)$ & 2400 \\
\hline & & Cp (Specfic Heat) (j/kg-k) & 880 \\
\hline & & Thermal Conductivity (w/m-k) & 1 \\
\hline & & Initial temperature $(\mathrm{k})$ & 318.15 \\
\hline \multirow[t]{11}{*}{ Operating Conditions } & Enclosure (air) & Operating Pressure (pascal) & 101325 \\
\hline & & Gravity Acceleration $\left(\mathrm{m} / \mathrm{s}^{2}\right)$ & -9.81 \\
\hline & & Operating Temperature (k) & 297.85 \\
\hline & & Velocity Magnitude (m/s) & 3.5 \\
\hline & Inlet & Inlet Temperature $(\mathrm{k})$ & 297.85 \\
\hline & & Turbulent Intensity (\%) & 1 \\
\hline & & Turbulent Viscosity Ratio & 10 \\
\hline & Outlet & Gauge Pressure (pascal) & 0 \\
\hline & & Backflow Turbulent Intensity (\%) & 5 \\
\hline & & Backflow Turbulent Viscosity Ratio & 10 \\
\hline & & Backflow Total Temperature (k) & 297.85 \\
\hline
\end{tabular}

Table-III: Ten ranges and their respective deviated temperature
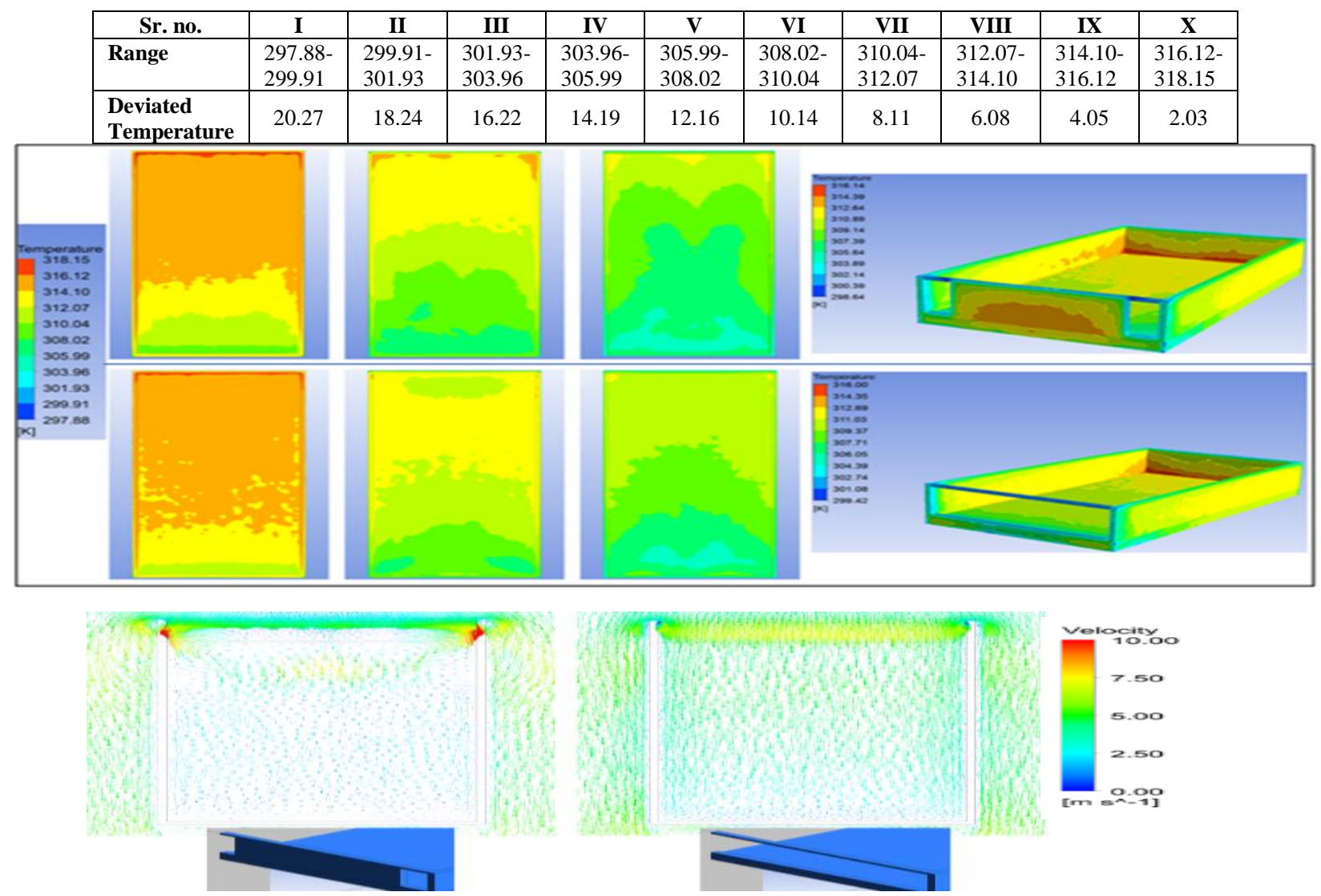

Fig. 7: Visual comparison for heat loss during ANSYS-Fluent simulation between scenarios S5 \& S16 at an interval of 3600,7200 and 10800 seconds 
For analysing post-simulation data, a concept of Area Weighted Temperature Loss (AWTL) was devised. During each simulation, the roof surface, which was initially evenly patched to $318.15 \mathrm{~K}$, was exposed to varied airflow patterns generated out of the sixteen templates of parapet respectively. This resulted in a unique convective cooling profile for each scenario with surface temperature ranges from $318.15 \mathrm{~K}$ (initial surface temperature) to $297.85 \mathrm{~K}$ (ambient air temperature). This was because the lowest temperature for any part of the roof surface can be in equilibrium with an ambient air temperature of $297.85 \mathrm{~K}$. This range of temperature from $318.15 \mathrm{~K}$ to $297.85 \mathrm{~K}$ was divided into ten equal parts with a difference of $2.03 \mathrm{~K}$. After the simulation, the temperature of each surface was divided into ten zones which corresponded to the deviated temperature, as stated in table number 3. The amount of temperature loss from each zone was then multiplied by the respective surface area to get AWTL for ten individual zones. Later, these values were summed up to get the AWTL by an individual roof surface. Lastly, AWTL from all the 16 scenarios were compared among themselves. Scenarios with higher AWTL value donates more heat loss which makes them suitable comparison to others.

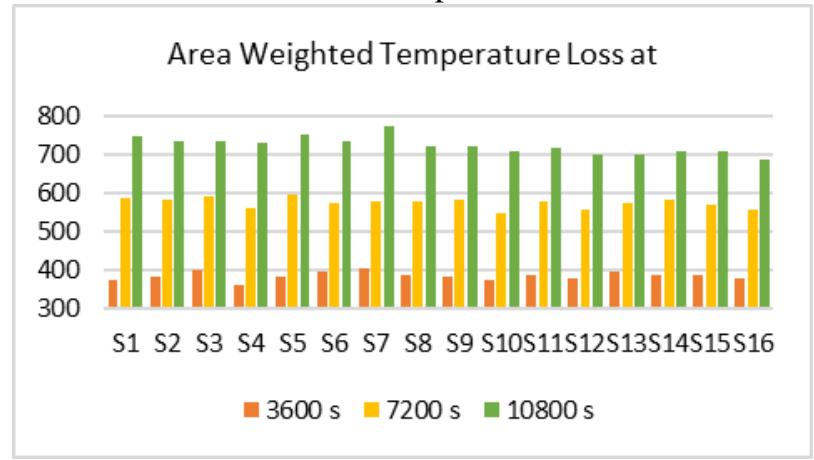

Fig. 8: Airflow profile in plan and section during ANSYS-Fluent simulation for scenarios S5 \& S16 at an interval of 3600 seconds
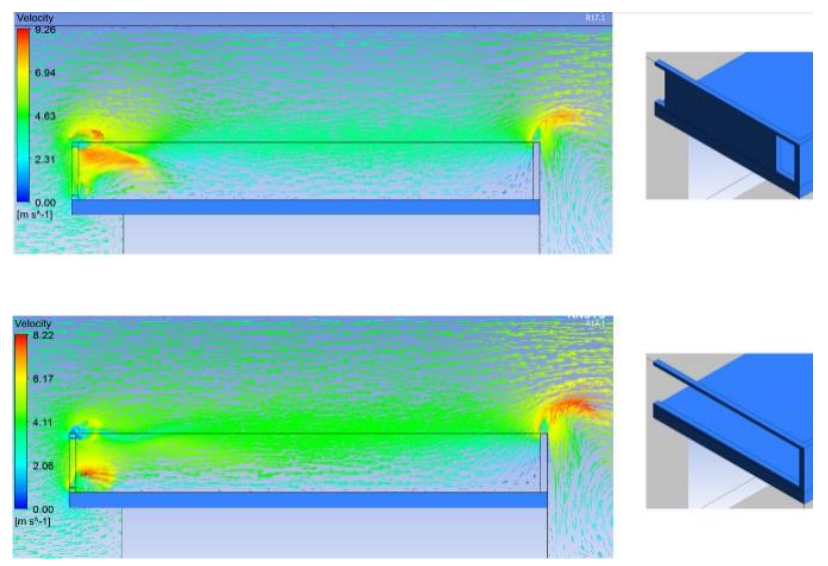

Fig. 9: Area weighted temperature loss by sixteen scenarios after $3600 \mathrm{~s}, 7200 \mathrm{~s}$ and $10800 \mathrm{~s}$

\section{B. Phase II- Physical Model study:}

Two scenarios S5 and S10 were picked out of the 16 scenarios based on their deviating performance. They were positioned at the top and bottom section of the performing list based on the simulation results. For the environmental analysis, their reduced three-dimensional proportionate models were made. The walls and the load-bearing frame were made from cardboard and wooden battens, so they have minimal impact on slab due to thermal conduction. The slab was made of Kota stone, to have similar behaviour of the thermal mass of concrete. The instruments which were used during the experiment were NEC Thermo Shot thermal imaging camera, Mextech J411TH digital hygro thermometer and Kaindl Windtronic 2 digital wind meter.

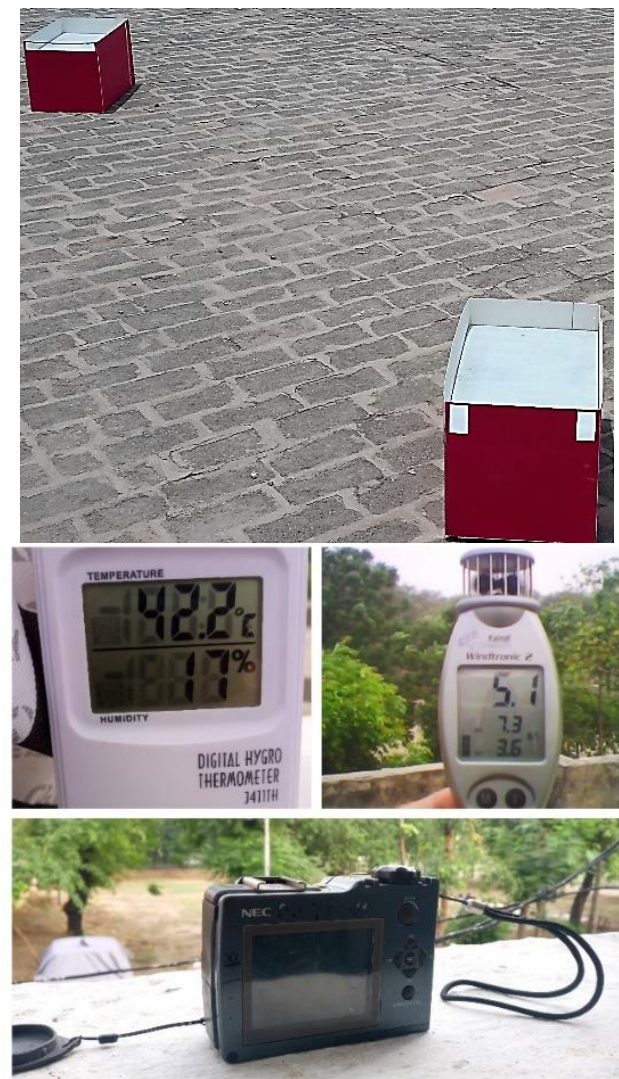

Fig. 10: The physical model for scenario S5 and S10 and images of the instruments used during the outdoor experiment. Source: author 


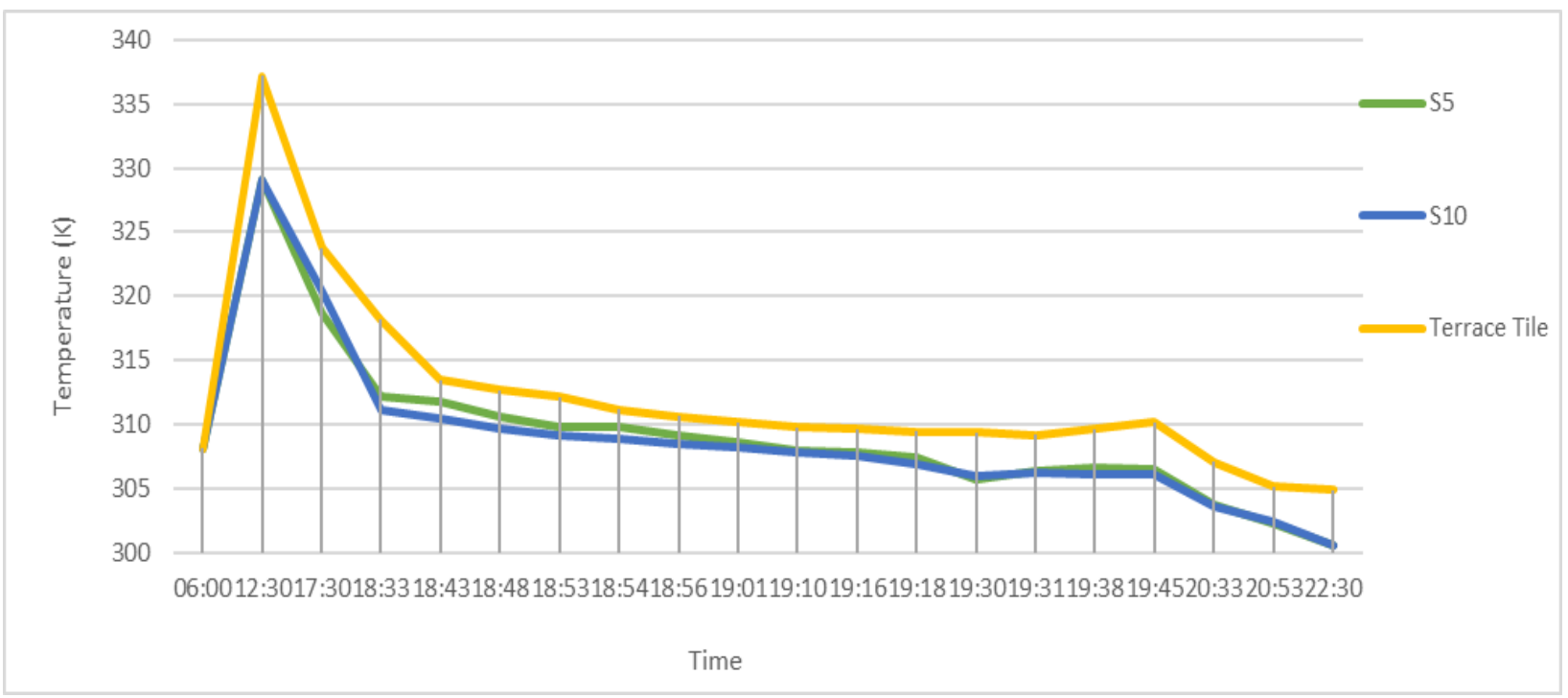

Fig. 11: Surface temperature of the stone slab for scenario S5, S10 and tile terrace

Based on the weather report, a day was picked during the peak summer season which had a prediction of amply sunshine before an overcast evening with cooling airflow. This order of change in weather was the perfect scenario for analysing convective cooling of slabs in a limited period. Kota stone slabs were placed outside on the terrace of a twostory building a day before the experiment to keep their thermal values in equilibrium with the surroundings. Later the stone slabs were placed on their frame, and the model was oriented so that the front parapet wall with voids faces the incoming airflow. Both the units were far from any obstruction and were fully exposed to sunshine. A thermal image camera was used to record the pattern of heating/ cooling of the slab at a regular interval. Later the images and their respective readings were compared to map the pattern of heat loss among themselves and with their corresponding digital scenarios.

\section{RESULT AND DISCUSSION}

- During the CFD simulation, the performance of scenarios was relative to the percentage of openings, as the size of voids increases their efficiency decreases. Dual vertical performed well within the group of parapets with the same percentage of opening. The efficacy of the parapet with no opening improved as time passes. On the contrary, the effectiveness of parapet with large voids decreased. In a similar fashion parapet with narrow check voids maintained top slots whereas relatively broader check voids performance dropped swiftly as the time passed. Horizontal down void showed better capability about their counterpart horizontal up void with the same opening area. Lastly, parapets with openings in the centre showed average results which were followed by multiple vertical openings in their respective slots with the same solid to void ratio.
Table No. IV: Scenarios are grouped into four numbers according to their response during AWTL:

\begin{tabular}{|c|l|l|l|}
\hline Sr No & Scenario & Performance & Generic Name \\
\hline 1 & S7, S5, S1, & Excellent & $\begin{array}{l}\text { 20\% Grid, 20\% Dual Vertical, 0\% } \\
\text { Opening, 20\% Horizontal Down }\end{array}$ \\
& S3 & & 20\% Centre, 20\% Multiple Vertical, \\
2 & S2, S6, S4, & Good & \\
& S9 & & Down Horizontal Up, 40\% Horizontal \\
\hline 3 & S8, S11, & Average & $\begin{array}{l}40 \% \text { Centre, 40\% Dual Vertical, } \\
60 \% \text { Dual Vertical, 40\% Horizontal }\end{array}$ \\
& S15, S10 & & Up \\
\hline 4 & S14, S12, & Fair & $60 \%$ Centre, 40\% Multiple Vertical, \\
& S13, S16 & & $40 \%$ Grid, 80\% Centre \\
\hline
\end{tabular}

Physical model study has shown that high ambient temperature with low humidity of $315.45 \mathrm{~K}$ and $17 \%$ respectively resulted in heating up of stone surface to 329.15 $\mathrm{K}$ and terrace roof tile on which models were placed to $337.15 \mathrm{~K}$. By late evening when the ambient temperature dropped to $305.95 \mathrm{~K}$ the convective process cooling of the surfaces was visible through thermal images. By this time, average air velocity was around $3.5 \mathrm{~m} / \mathrm{s}$ with a few gusts of air reaching beyond $10 \mathrm{~m} / \mathrm{s}$. An increase in humidity from $17 \%$ to $33.5 \%$ also contributed to the cooling process of the surfaces.

- $\quad$ Because it was an outdoor experiment, the cooling down of the surfaces was not only because of the convective cooling by the passing air. Still, it was one of the driving factors as the thermal images captured variation in hot and cold zones, which was in response to the difference in the profile of the voids for scenario S5 and S10. Vertical voids along the edges in scenario S5 directed the flow along the adjoining wall; on the contrary, in scenario S10 incoming air spread evenly along the surface. By late evening, the thermal patterns were asymmetric along the longitudinal axis due to a little deviation in the direction of incoming airflow, which was initially perpendicular to the front parapet wall. Among the scenarios, an average difference of $0.29 \mathrm{~K}$ was observed in the surface temperature. The order of heat gain and loss by the stone tile surface was like the kiln backed brick tile surface 


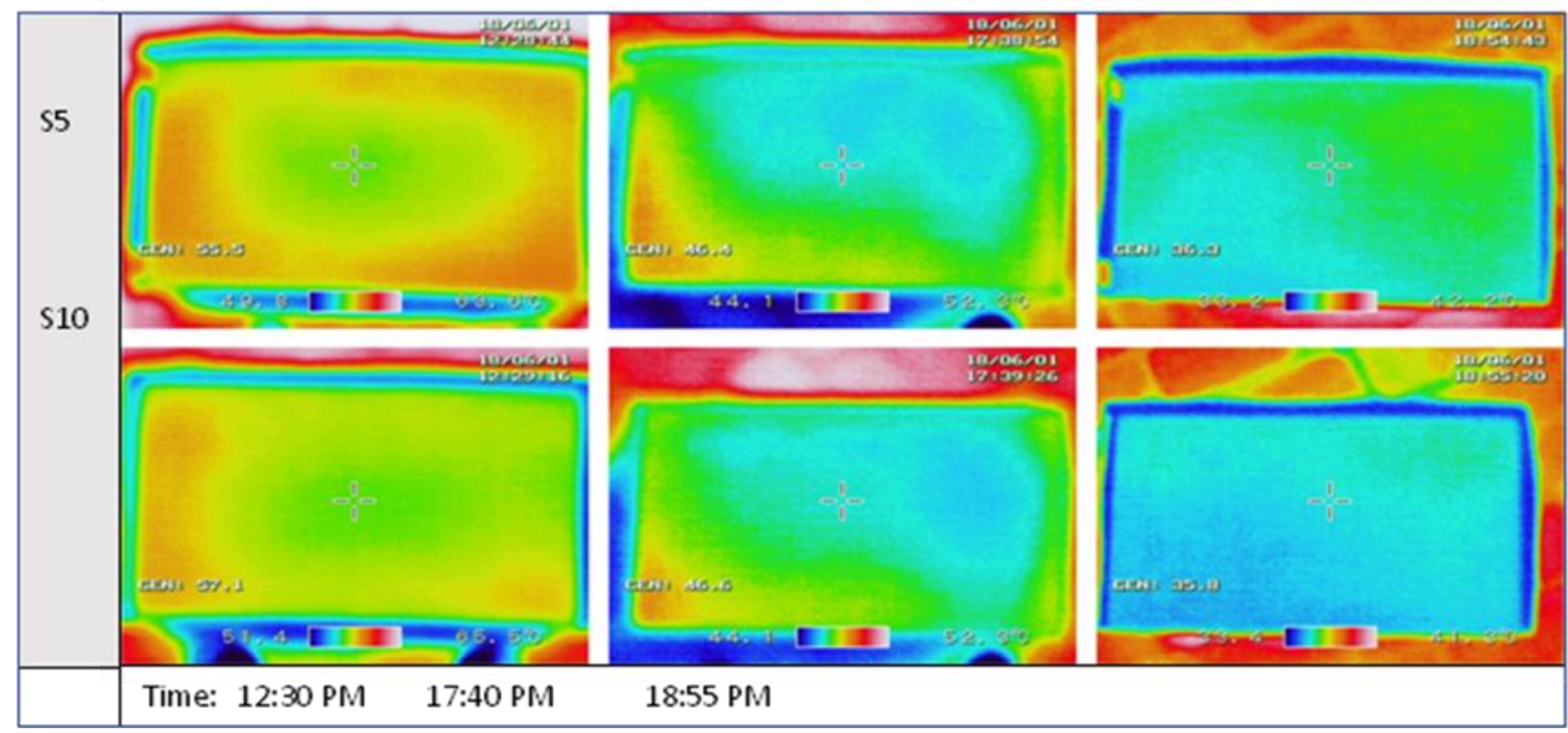

Fig. 12: Thermal images of slabs for scenario S5 and S10 captured at different timelines. Source: author

- pattern was not alike due to variation in the participating elements. But one common thing which was prominent among all of them was the effect of voids on the behaviour of airflow. The time taken for the drop in the surface temperature from the day high to ambient air temperature at an average air velocity of $3.5 \mathrm{~m} / \mathrm{s}$ was also somewhat similar. This validates the role of voids for the cooling of the surfaces. Because during the digital model, all other environmental aspects were constant except the airflow, so it is justified to accept the order of performance as recorded for convective cooling based on digital simulation.

\section{CONCLUSION}

Clearly, the effect of convective cooling for roof surface can be seen due to the variation in the design of voids during, as observed during CFD simulation and scaled model analysis. The critical reasons for the better performance include I) narrow openings which lead to deeper flow with higher velocity ii) openings near to the roof surface for more extensive contact iii) opening near the adjoining parapet wall which leads to inward diversion of airflow towards roof surface iv) Solid parapet surface diverted airflow downwards to roof v) Longer contact period. One can pick from the best performing set and modify the generic parapet design with concerns to privacy, security and aesthetics; while keeping in mind the abovestated measures.

There is ample scope to use this untapped knowledge during the execution of individual, mass-housing project meant for EWS and LIG. Along with this, all the other rooftop activities can get extended time benefit with shorter thermal stress period. The learnings can be applied in all those areas which have hot-dry or composite climate with the availability of adequate airflow. There is further scope of the study, for accelerating the cooling process by clubbing this passive design strategy with another, i.e. evaporative cooling.

\section{REFERENCES:}

1. K. S. Ahmed, "Comfort in urban spaces: defining the boundaries of outdoor thermal comfort for the tropical urban environments," Energy Build., vol. 35, no. 2003, pp. 103-110, 2003.

2. ANSYS, "Choosing the Spatial Discretization Scheme," SAS IP, Inc., 2017. [Online]. Available: help/flu_ug/flu_ug_sec_solve_choose_disc.html.

3. E. Prianto and P. Depecker, "Characteristic of airflow as the effect of balcony, opening design and internal division on indoor velocity: A case study of traditional dwelling in urban living quarter in tropical humid region,” Energy Build., vol. 34, no. 4, pp. 401-409, 2002, doi: 10.1016/S0378-7788(01)00124-4.

4. S. Al-Azzawi, "Indigenous courtyard houses," Renew. Energy, vol. 5, no. 5-8, pp. 1099-1123, Aug. 1994, doi: 10.1016/0960 1481(94)90137-6.

5. I. Chand, V. K. Sharma, and N. L. V Krishak, "Ventilation survey of typical airy buildings-A few case studies in hot dry and hot humid zones of India,” Build. Environ., vol. 24, no. 3, pp. 229-238, 1989, doi: 10.1016/0360-1323(89)90036-X.

6. AFP News Agency, "3 Killed as Kite String Slits Throats in India," The Daily Star, 2016. [Online]. Available: https://www.thedailystar.net/world/3-killed-kite-string-slits-throatsindia-1271173. [Accessed: 20-Jan-2020].

7. "JJ in Africa - Page 3-6 months on (and off) the road," 2016. [Online]. Available: https://jjinafrica.wordpress.com/page/3/. [Accessed: 20-Jan-2020].

8. "Rooftop Dreams - Yasmin Mund." [Online]. Available: https://yasminmund.com/shop/rooftop-dreams-fine-art-soft-cottonprint. [Accessed: 20-Jan-2020].

9. M. A. Mohsen, "Solar radiation and courtyard house forms-I. A mathematical model," Build. Environ., vol. 14, no. 2, pp. 89-106, Jan. 1979, doi: 10.1016/0360-1323(79)90014-3.

10. M. Majumdar, Energy-efficient Buildings in India. New Delhi: The Energy and Resources Institute (TERI), 2001

11. C. Correa, "The Blessings of the Sky," Work Charles Correa, pp. 1728, 1996.

12. G. Eggenspieler, "Advanced Turbulence Modeling Methods Provide Accurate, Efficient Results in Any Fluid Flow Application," ANSYS, Inc, no. 408, pp. 1-5, 2013. 
13. BIS, National Building Code of India 2016, vol. 1. Nodia: Bureau of Indian Standards, 2016

14. S. Huler, Defining the Wind: The Beaufort Scale and How a 19thCentury Admiral Turned Science into Poetry, 2nd ed. Broadway Books, 2005.

\section{AUTHORS PROFILE}

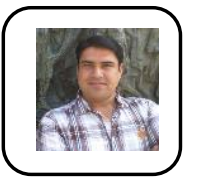

Ar. Kapil Arora is a part-time $\mathrm{PhD}$ research scholar at Indian Institute of Technology Roorkee, Roorkee, India. He is currently working as Assistant Professor at GZS School of Architecture \& Planning, MRSPTU, Bathinda, India. He is a member of Council of Architecture, New Delhi. He is engaged in Architectural practice through institutional consultancy cell. He has currently designed faculty housing units and entrance gate for Punjab State Aeronautical Engineering College, Patiala. He has been awarded as the best paper presenter at IITR during an international conference with the theme; Sustainable Built Environment. He has experience of teaching for more than ten years. Under the guidance of Dr Mahua Mukherjee, he has completed a research project sponsored by BMTPC, New Delhi. He has successfully assisted during national workshops and seminars at different platforms. He has taught and guided students from M Arch, M Planning and B Arch courses. His academic contributions include formation and revision of syllabus for MRSPTU, Bathinda, LPU, Phagwara. He is also holding an administrative position of Deputy In-charge (Academics) at MRSPTU, Bathinda. His publications majorly focused on areas like affordable housing, climate responsive design, disaster-resistant architecture. He has been delivering sessions during ECBC workshops being held at the regional level.

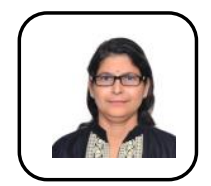

Dr Mahua Mukherjee is working as Professor at the Department of Architecture and Planning in Indian Institute of Technology Roorkee, India. Currently, she is also working as Head of Department at Centre of Excellence in Disaster Mitigation and Management, IITR. Her memberships for institutes include Council of Architecture India, Indian Institute of Architects, International Council for Research and Innovation in Building and Construction (CIB), The Association of Engineers, Centre for Built-Environment India, India Habitat Forum (INHAF) India, Fulbright Alumni Association. She is having publications in more than 35 Refereed Journal Papers. She has completed around six sponsored research projects. Till now Seven students have completed a $\mathrm{PhD}$ under her guidance. She herself completed a $\mathrm{PhD}$ in the year 2003 from Jadavpur University Kolkata. She has participated in several national and international seminars all over the world. She has served on administrative positions at IIT during her service. Her abroad visits related to knowledge exchange includes 2018 Nov-Dec Tohuku University, Japan, October Beijing Normal University, China, August City College, USA, Penn State University, USA, Illinois Institute of Technology, USA, March Kyoto University, Japan, 2017 June Seville, Spain, 2016 Jan, April-June Kyoto University, Japan, April, June Tokyo University, UN University Tokyo, 2013 June Czech Technical University, Prague, 2011 June University College of London, UK, 2010 January National University of Singapore, Singapore, June University of the Witwatersrand, Johannesburg, South Africa, 2008 Jan-May Penn State University, USA (As Fulbright Fellow), 2007 Feb-March San Jose, Costa Rica. She has published three chapters and has edited two books. 